\title{
Análise da Eficiência do GPR na Estimativa da Biomassa de Tubérculos
}

Guilherme Zakarewicz de Aguiar, Amanda Rocha, Susanne Maciel e Welitom Rodrigues Borges

Copyright 2019, SBGf - Sociedade Brasileira de Geofísica

This paper was prepared for presentation during the $16^{\text {th }}$ International Congress of the Brazilian Geophysical Society held in Rio de Janeiro, Brazil, 19-22 August 2019.

Contents of this paper were reviewed by the Technical Committee of the $16^{\text {th }}$ International Congress of the Brazilian Geophysical Society and do not necessarily represent any position of the SBGf, its officers or members. Electronic reproduction or storage of any part of this paper for commercial purposes without the written consent of the Brazilian Geophysical Society is prohibited.

\section{Abstract}

The cultivation of tubers play an important role in brazilian economy and population nourishment. Thus the detection and quantification of the size and biomass produced by tubers in agroforestry or conventional agricultural systems are relevant. Ground-penetrating radar (GPR) provides a cheap and non-invasive method for underground root biomass investigation. Tubers biomass estimation is studied within a controlled GPR acquisition in a sandbox. Results show that the accuracy of diameter estimation is poor, although the GPR is able to provide other indexes for biomass estimation.

\section{Introdução}

A atual emissão dos gases do efeito estufa (GEE) na atmosfera, entre eles o dióxido de carbono, aumenta a importância das discussões de como reduzir as fontes de tais gases e de desenvolver estratégias que promovam o sequestro de carbono. Reconhece-se a necessidade de estudos específicos de cálculos de captura de carbono que geralmente são feitos baseados em dados já existentes de produção de biomassa e que não correspondem às formações florestais (Arevalo et al., 2002). A compra e venda de créditos de carbono é uma das tentativas internacionais de fomentar a diminuição dos efeitos dos GEE na atmosfera. O protocolo de Kyoto estabeleceu regras em que empresas de países desenvolvidos podem financiar a implementação e manutenção de projetos de redução ou remoção dos GEE em países em desenvolvimento; dessa forma, os países em desenvolvimento terão recursos para buscar o desenvolvimento sustentável e os países desenvolvidos terão compensado a poluição que produzem e que, por razões diversas, não conseguem eliminar (Ribeiro, 2005). Destaca-se a importância de projetos de reflorestamento e procedimentos sustentáveis de plantio, uma vez que o uso de práticas de manejo florestal e agroflorestal pode potencialmente mitigar e reduzir as emissões de carbono, ou seja, sequestrando-o, capturando-o e mantendo-o o maior tempo possível na biomassa (Arevalo et al., 2002).
Segundo Philippi (1999), as frutas e hortaliças são alimentos comuns à dieta por serem de fácil acesso à população. Souza (2009) afirma que as hortaliças representam $16 \%$ dos alimentos consumidos pela população brasileira. Os tubérculos são importantes para a economia e alimentação; a cenoura (Daecus carota L.), por exemplo, é cultivada o ano todo (Resende, 2005). O cultivo da batata doce, por sua vez, está distribuído por todo o país, o que se deve, além da riqueza nutricional, à capacidade de produção em solos fracos, à baixa incidência de doenças limitantes e à baixa exigência em manejo (Khatounian, 1994). O cará pode ser utilizado como substituto da batata inglesa, batata doce e macaxeira, com a vantagem de não se deteriorar logo após a colheita (Azevedo, 1998). Em solos de fertilidade mediana, podem ser esperadas, como normais, colheitas superiores a 20 toneladas do tubérculo por hectare (Azevedo, 1998). Dessa forma, os vegetais, legumes e tubérculos representam uma parcela significativa da biomassa do país.

Um sistema apresenta biomassa tanto aérea quanto em subsuperfície. O cálculo da biomassa aérea pode ser feito com o uso de equações alométricas, a partir de uma série de medidas feitas nos caules e folhas das plantas no sistema. Já a biomassa de subsuperfície é tradicionalmente calculada a partir de medidas de pesos de amostras de raízes, coletadas ao longo de trincheiras. Para desenvolver as equações alométricas com boas predições sobre a biomassa total da árvore, são necessárias amostragens destrutivas das árvores (Arevalo et al., 2002). Uma das grandes dificuldades na determinação da quantidade de biomassa subsuperficial em um sistema é evitar os métodos invasivos comumente utilizados. Métodos de escavação tradicionais são destrutivos, com quantificação limitada e repetibilidade de medições ao longo do tempo. O GPR é usado como um método geofísico não destrutivo para delimitar as características de raízes em subsuperfície desde 1999 (Guo et al. 2013b).

Dentre tais características, destaca-se o diâmetro da raiz obtido após o processamento dos dados. A delimitação exata da fronteira entre a raiz e solo depende da profundidade do objeto enterrado, da velocidade de propagação da onda no solo e da frequência central da antena de aquisição. Para avaliar a eficácia do GPR para quantificação de biomassa de tubérculos, montamos um experimento controlado em uma caixa de areia, onde os tubérculos são enterrados. Posteriormente processamos e analisamos os radargramas adquiridos com uma antena de $2600 \mathrm{MHz}$. 
Análise da Eficiência do GPR na Estimativa da Biomassa de Tubérculos

\section{Metodologia}

Para os levantamentos de dados, foi utilizado o método geofísico GPR (ground-penetrating radar) com uma antena blindada de $2600 \mathrm{MHz}$ por meio da técnica do afastamento comum. Utilizamos como alvos raízes com diâmetro superior a $4 \mathrm{~cm}$ (Tabela 1), caracterizadas como grossas (Guo et al. 2013b, Resh et al. 2003), comestíveis e comuns no território brasileiro. As amostras estavam frescas, ideais para o levantamento, pois o teor de água nas raízes é um fator importante para a detecção (Guo et al. 2013a, Hirano et al. 2009). Foram enterradas em um ambiente controlado - caixa de areia (Figura 1). A aquisição em solos arenosos é favorável à detecção e quantificação de raízes (Butnor et al. 2005). Todos os alvos foram enterrados paralelos ao solo, e a aquisição foi feita transversalmente, para otimizar a interação com as ondas eletromagnéticas do radar.

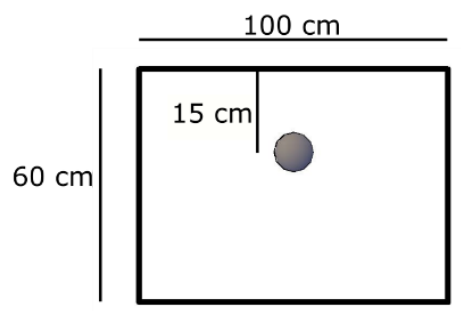

Figura 1 - Esquema e dimensões da caixa de areia em que as aquisições foram realizadas.

\begin{tabular}{|l|c|c|c|}
\hline \multicolumn{1}{|c|}{ Raiz } & $\begin{array}{c}\text { Comprimen } \\
\text { to }(\mathrm{cm})\end{array}$ & $\begin{array}{c}\text { Diâmetro } \\
(\mathrm{cm})\end{array}$ & $\begin{array}{c}\text { Profundidad } \\
\mathrm{e}(\mathrm{cm})\end{array}$ \\
\hline Cenoura & 24 & 4.5 & 13 \\
\hline B. Doce & 29.5 & 6 & 13 \\
\hline B. Inglesa & 13 & 8 & 15 \\
\hline Beterraba & 11 & 10 & 15 \\
\hline Inhame & 15.5 & 7 & 13.5 \\
\hline Cará & 17.5 & 9.5 & 15 \\
\hline
\end{tabular}

Tabela 1 - Medidas das raízes utilizadas como alvos nas aquisições e profundidade em que foram enterradas.

Aplicamos as mesmas etapas de processamento para todos os dados adquiridos. Utilizamos o software Reflex-Win versão 7.5 (Sandmeier Scientific Software, Karlsruhe, Alemanha). Com base nas propriedades físicas da areia, foi gerado um modelo de velocidade para o empilhamento das amplitudes. Tal processo está exemplificado na Figura 2. Etapas semelhantes foram realizadas em trabalhos anteriores, como por Guo et. al. (2013a).

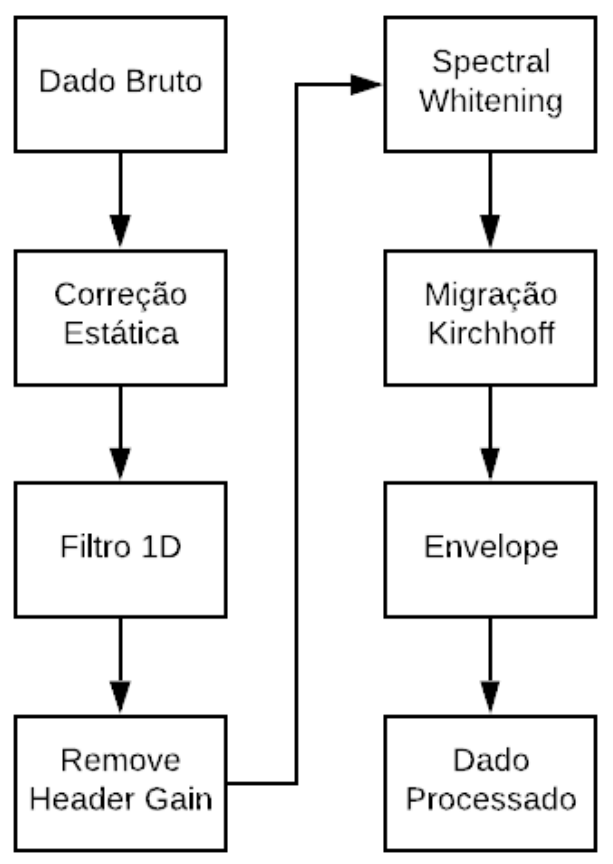

Figura 2 - Fluxograma com as etapas do processamento aplicado aos dados.

1 - Correção Estática

A Correção Estática é necessária devido ao fato da onda aérea ser assumida como tempo com valor igual a zero. O Set Time Zero objetiva eliminar o efeito da onda direta e realiza a correção do tempo zero (Furtado, 2009). Este passo do processamento faz com que o tempo zero corresponda à superfície em que a antena foi posicionada, o que faz com que todos os alvos e estruturas identificados em subsuperfície tenham seus valores de tempo duplo corretamente ajustados (Lima, 2006).

2 - Filtragem Temporal 1D

O filtro 1D faz com que ruídos sejam eliminados e $\mathrm{o}$ alvo seja realçado. Foi aplicado o filtro Bandpass Butterworth. Os limites para o corte de frequência foram determinados após visualização do espectro de amplitude no domínio FK, como feito no trabalho de Furtado (2009).

\section{3 - Remove Header Gain}

No momento da aquisição, o próprio equipamento vem programado para dar um ganho no sinal. Esta etapa remove este ganho, que é artificial, para que possamos processar o dado bruto.

4 - Spectral Whitening

O Spectral Whitening compensa a atenuação da frequência pelo tempo. Ocorre um achatamento do espectro de uma dada banda de frequência (Sandmeier, 2011). Essa etapa do processamento visa suavizar as amplitudes do dado para que a migração seja mais precisa. Foi aplicado para todo o intervalo de tempo que compreende o dado. 
DE AGUIAR, G. Z., ROCHA, A. A., MACIEL, S. T. R., BORGES, W. R.

\section{5 - Kirchhoff}

A migração Kirchhoff consiste em um empilhamento das amplitudes do sinal, colapsando as hipérboles em um ponto, permitindo uma visualização da intensidade da amplitude do sinal de um objeto. Nessa etapa, é feita a conversão do tempo para profundidade através do cálculo da velocidade de ajuste hiperbólico encontrada nas raízes (Rocha et al., 2012).

\section{6 - Envelope (transformada de Hilbert)}

Utiliza-se a transformada de Hilbert para calcular o envelope (ou valor de amplitude do sinal analítico). $O$ sinal analítico é o sinal complexo cuja parte real é o sinal adquirido e a parte imaginária é dada pela transformada de Hilbert. É proporcional à raiz quadrada da energia do sinal em um momento instantâneo do tempo. Essa etapa proporciona uma visão geral da energia dos traços migrados (Sandmeier, 2011).

\section{Resultados}

A Figura 3 ilustra os resultados obtidos na aquisição da cenoura. Na Figura 3.1, foi realizada a correção estática, com os parâmetros: tempo $=2,0889$ ns e distância = $0,2029 \mathrm{~m}$. Na 3.2, foi realizada a filtragem temporal 1D Bandpass Butterworth, com o corte superior de $4000 \mathrm{~Hz}$ e inferior de $1200 \mathrm{~Hz}$. Na 3.3 foi retirado o ganho artificial do equipamento para todos os traços do dado. Na 3.4, foi aplicado o Spectral Whitening, com os parâmetros: frequência inicial $=0 \mathrm{~Hz}$, frequência final $=2300 \mathrm{~Hz}$ e valor de escala $=1$. $\mathrm{Na} 3.5$, foi feita a migração Kirchhoff, com os parâmetros: summation width $=70$, velocidade $=$ $0,2 \mathrm{~m} / \mathrm{ns}$, tempo inicial $=0 \mathrm{~s}$ e tempo final $=9,9609 \mathrm{~s}$. Na 3.6, foi realizado o envelope em todos os traços do dado. Por fim, na 3.7, a escala de cor foi trocada para Rainbow2.

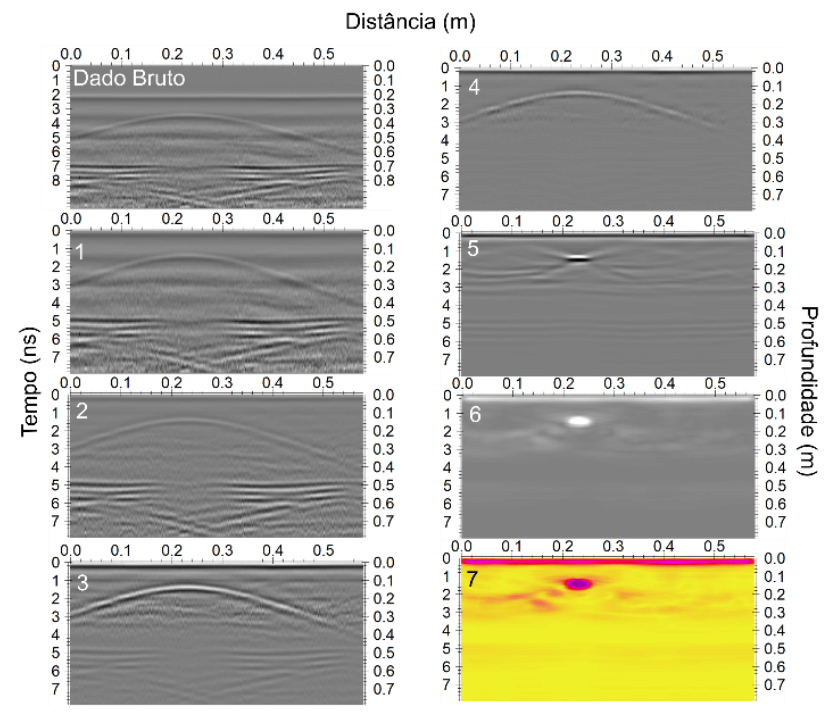

Figura 3 - Radargramas sequenciando os resultados do processamento do dado da cenoura.

As amplitudes obtidas na sessão resultante na última etapa do processamento é utilizada para extrair parâmetros indicadores da biomassa presente no tubérculo. É possível observar uma correlação entre o comprimento das raízes e os mais altos valores de amplitude do sinal: quanto maior o comprimento, mais alta a amplitude. Em ordem decrescente: cenoura, cará, batata doce, inhame, batata inglesa e beterraba (Tabela 1). Isso se deve ao fato de o sinal do GPR ser espalhado na subsuperfície em forma cônica, mesmo que o levantamento seja feito em 2D (Figura 4). A amplitude do sinal pode ser interpretada como o resultado de uma integral da superfície do objeto, que por sua vez, depende de suas medidas nas três dimensões. Isto é, objetos mais compridos tendem a apresentar resultados mais precisos na migração.

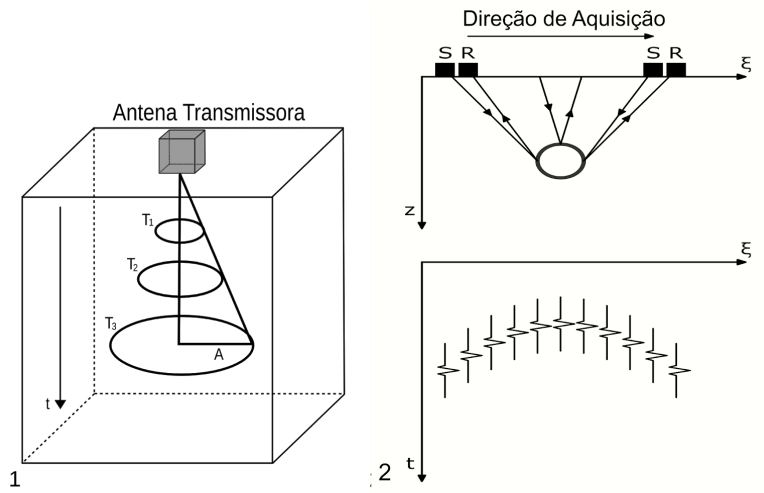

Figura 4 - (1) Esquema do espalhamento cônico das ondas de GPR; (2) o espalhamento cônico permite o sinal ser refletido por um objeto enterrado antes e depois da antena estar diretamente acima deste. Abaixo, exemplos de amplitudes geradas que formam a hipérbole.

Ao se comparar as dimensões das circunferências geradas pelo envelope com o diâmetro real das raízes, como exemplificado pela Figura 5 , nota-se que há divergência entre os valores. Foram calculados os erros relativos entre o diâmetro real de cada tubérculo e o diâmetro estimado após o processamento de dados. Para isso, exportamos o traço central de cada dado e elaboramos um gráfico amplitude $\mathrm{X}$ profundidade (Figura 6) utilizando o programa Python. Consideramos como diâmetro estimado 0 intervalo entre dois pontos correspondentes a $60 \%$ do maior valor de amplitude fornecida pelo dado. Nota-se que o maior erro foi percebido na beterraba, que se aproxima mais de uma esfera do que um cilindro. 
Análise da Eficiência do GPR na Estimativa da Biomassa de Tubérculos

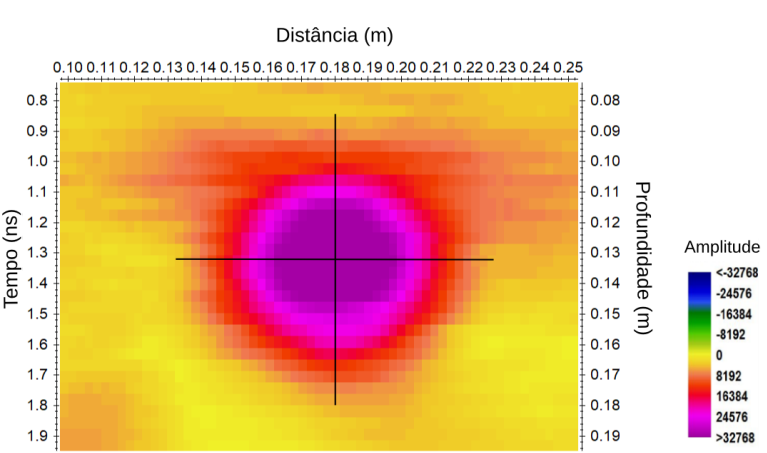

Figura 5 - Radargrama gerado pelo processamento do dado adquirido (cará). O diâmetro real do tubérculo (cruz preta) foi traçado por cima do perfil GPR para melhor visualização de sua discrepância com o diâmetro da mancha gerada pelo processamento.

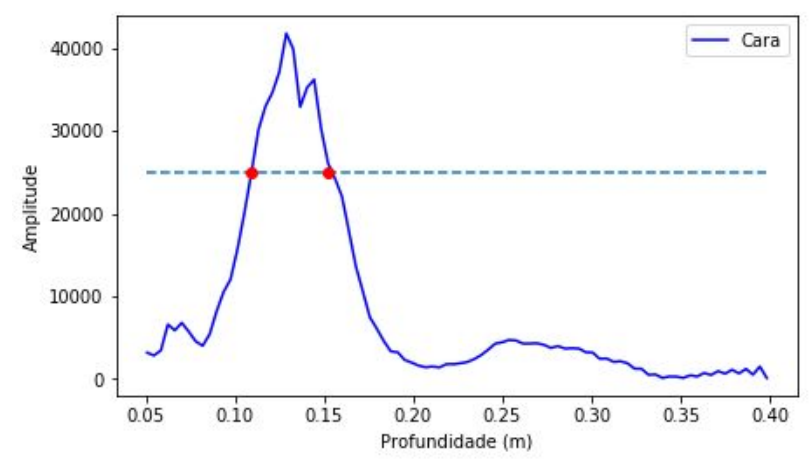

Figura 6 - Gráfico com o traço central do cará após a transformada de Hilbert (azul). Em azul tracejado, o valor correspondente a $60 \%$ da máxima amplitude; em vermelho, os pontos que representam $60 \%$ da amplitude máxima. Diâmetro real do cará: $9.5 \mathrm{~cm}$. Diâmetro estimado: $4.29 \mathrm{~cm}$. Erro relativo: $54.84 \%$.

A Figura 7 mostra o gráfico do erro relativo em função da razão comprimento/diâmetro. É possível observar que há uma tendência da diminuição do erro com o aumento do comprimento em relação ao diâmetro. Espera-se que o tamanho da mancha gerada pelo colapso da hipérbole do dado se aproxime do valor do diâmetro real de amostras cujo formato seja cilíndrico.

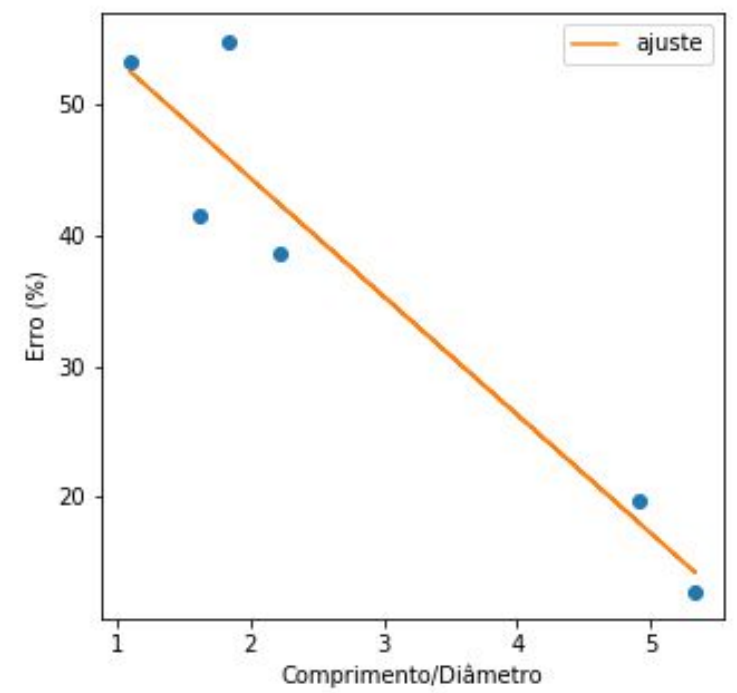

Figura 7 - Gráfico da relação entre o erro relativo (em porcentagem) e a razão comprimento/diâmetro de cada amostra.

Pode-se considerar que a aproximação entre os valores de diâmetro reais das raízes e os valores obtidos pelo método proposto é satisfatória.

É importante frisar que o programa de processamento possui um limite automático de amplitude de valor 32768. Pode-se notar tal corte na Figura 8, que mostra o traço central do dado da batata doce exportado após o envelope. Assim, a imagem gerada pelo Reflex após o processamento pode não ser representativa e a interpretação é prejudicada. Para a análise dos valores de amplitude, exportarmos os traços após a migração (Figuras 9 e 10) e realizamos a transformada de Hilbert pelo Python para representar traços após o envelope (Figura 11).

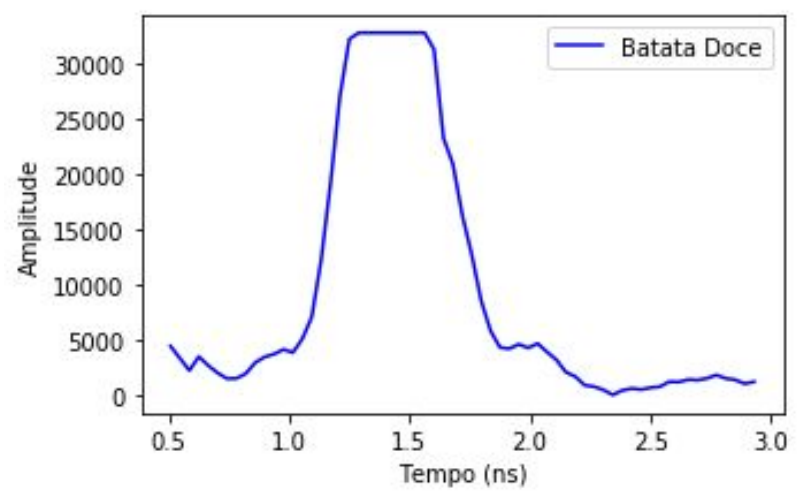

Figura 8 - Traço central da batata doce após o envelope feito no Reflexw. É possível notar um limite próximo ao valor de amplitude igual a 30000.

Após analisarmos os traços exportados, notamos uma correlação entre os tubérculos de acordo com os valores de amplitude. A Figura 9 mostra que as três raízes com maiores valores de amplitude são a cenoura, cará e batata doce, que possuem maiores comprimentos. Já as 
DE AGUIAR, G. Z., ROCHA, A. A., MACIEL, S. T. R., BORGES, W. R.

três raízes com menores valores de amplitude são o inhame, batata inglesa e beterraba, representadas na Figura 10.

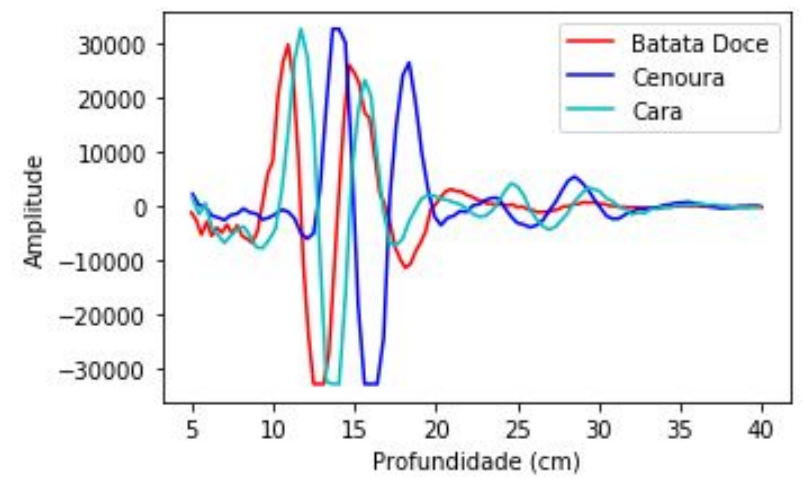

Figura 9 - Gráfico amplitude x profundidade com traços exportados após a migração Kirchhoff (batata doce, cará e cenoura).

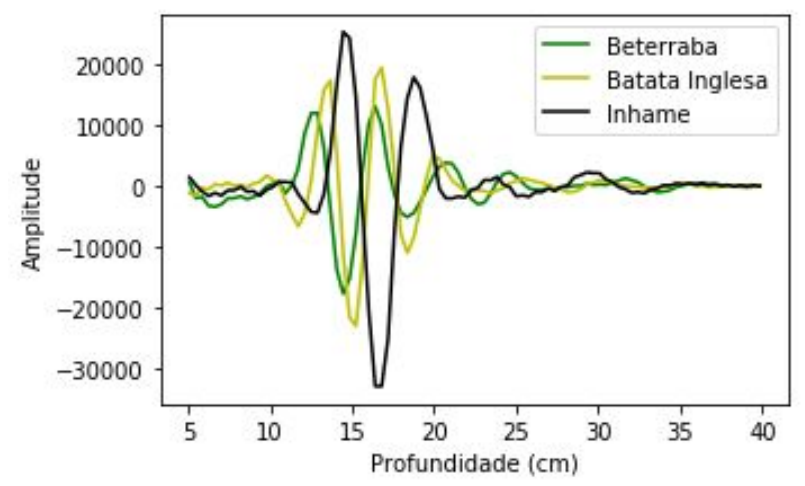

Figura 10 - Gráfico amplitude x profundidade com traços exportados após a migração Kirchhoff (batata inglesa, beterraba e inhame).

A Figura 11 mostra o traço central das sessões resultantes da transformada de Hilbert aplicada sobre os dados migrados das aquisições transversais sobre a batata doce e a beterraba. Observe que a beterraba, cujo formato mais se aproxima de uma esfera, possui valor de amplitude menor que o da batata doce, cujo formato se aproxima de um cilindro, ainda que o diâmetro da beterraba seja maior que o da batata doce.

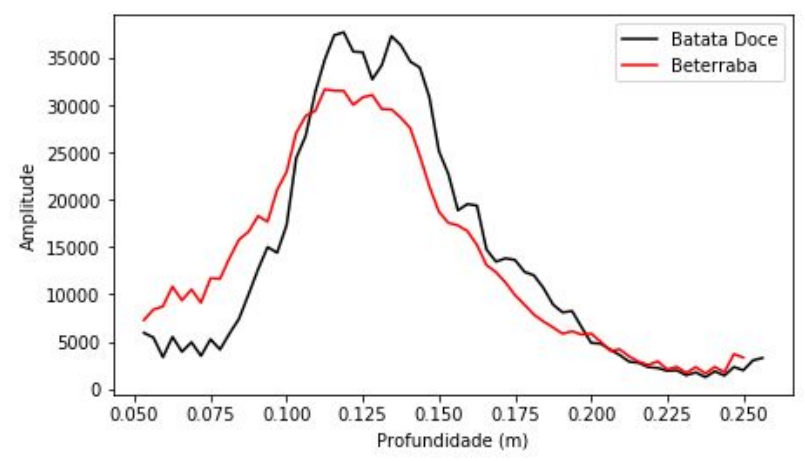

Figura 11 - Gráfico Amplitude x Profundidade com traços da batata doce e beterraba exportados após a transformada de Hilbert.

Os tubérculos enterrados nem sempre possuem diâmetro maior do que o limite de resolução de imageamento de um radargrama. Tubérculos com diâmetro menor do que o limite de resolução $(\lambda / 2, \lambda=$ comprimento de onda para a frequência do sinal) serão representados no radargrama por uma hipérbole de difração pura. Nestes casos é possível estimar a velocidade correta do meio, a partir de um ajuste de curva na hipérbole de difração. $O$ processo de migração irá colapsar esta hipérbole em uma mancha. O diâmetro desta mancha varia com o coeficiente de reflexão do alvo, e não necessariamente representa o diâmetro do tubérculo. Isso implica que o cálculo do diâmetro não é preciso. No caso em que o alvo possui diâmetro um pouco maior do que o limite de resolução, ele será representado por uma composição de hipérboles de reflexão geradas pelo do topo e pela base do tubérculo. No entanto, a distância entre os picos do topo e da base dependerá da velocidade de propagação da onda eletromagnética no interior do tubérculo, que por sua vez é controlada, entre outros fatores, pelo conteúdo de água no tubérculo.Portanto, a resolução vertical também é imprecisa para as dimensões do problema proposto. Além disso, é importante observar que neste caso, o ajuste de curva na hipérbole gerada não retornará a velocidade correta do meio, pois não é uma hipérbole de difração pura.

\section{Conclusões}

O método proposto apresenta resultados satisfatórios para a identificação e localização de raízes, e apresenta potencial para a estimativa da biomassa em subsuperfície de maneira indireta. Observamos que os parâmetros que controlam a qualidade das estimativas de diâmetro são a quantidade de água (ou a permissividade dielétrica), o diâmetro, a profundidade e o coeficiente de reflexão de cada tubérculo, mas o comprimento do alvo é uma característica que influencia diretamente a resposta do radar. O comprimento elevado da batata doce em relação à beterraba faz com que os valores de amplitude após o empilhamento se mostrem diretamente proporcionais à tal diferença. Dessa forma, para efeitos de identificação de raízes, o método se mostra conclusivo; já para a identificação e cálculo de volume dos tubérculos, parte fundamental no cálculo de biomassa, o processamento de dados aparenta necessitar mudanças.

A relação comprimento/diâmetro dos tubérculos é um ponto a ser discutido, pois variações no comprimento mostraram maiores efeitos nas amplitudes empilhadas do modelo do que variações de diâmetro. O fato de os levantamentos terem sido realizados em um ambiente controlado contribui para que os resultados apresentassem conclusões pertinentes.

Ponderamos que a precisão no cálculo do diâmetro dos tubérculos não é necessariamente um problema, tendo em vista que o objetivo do trabalho é estimar a biomassa em subsuperfície, e o cálculo de biomassa não depende 
Análise da Eficiência do GPR na Estimativa da Biomassa de Tubérculos

apenas do volume, mas também de outros parâmetros, como densidade, quantidade de água, etc. Estes parâmetros influenciam a resposta do radar, portanto estudos futuros consistem em determinar que parâmetros apresentam maior correlação com a quantidade de biomassa em subsuperfície.

\section{Referências}

AREVALO, Luis Alberto; ALEGRE, Julio Cesar; VILCAHUAMAN, Luciano Javier Montoya. Metodologia para estimar o estoque de carbono em diferentes sistemas de uso da terra. 2002.

AZEVEDO, JN de; DUARTE, R. L. R. Cultivo do cará. Embrapa Meio-Norte, Terezina, PI, n. 18, 1998.

BUTNOR, John R. et al. Utility of ground-penetrating radar as a root biomass survey tool in forest systems. Soil Science Society of America Journal, v. 67, n. 5, p. 1607-1615, 2003.

BUTNOR, John; ROTH, Brian; JOHNSEN, Kurt. Feasibility of using ground-penetrating radar to quantify root mass in Florida's intensively managed pine plantations. Forest Biology Research Cooperative Report \# 38. Gainsesville, FL 13 p., 2005.

FURTADO, C. P. Q. Processamento e modelagem de dados de GPR utilizando o Reflexw 4.5. Trabalho de Conclusão de Curso, UFP. 2009.

GUO, Li et al. Impact of root water content on root biomass estimation using ground penetrating radar: evidence from forward simulations and field controlled experiments. Plant and soil, v. 371, n. 1-2, p. 503-520, 2013-a .

GUO, Li et al. Application of ground penetrating radar for coarse root detection and quantification: a review. Plant and soil, v. 362, n. 1-2, p. 1-23, 2013-b.

HIRANO, Yasuhiro et al. Limiting factors in the detection of tree roots using ground-penetrating radar. Plant and Soil, v. 319, n. 1-2, p. 15, 2009.

KHATOUNIAN, Carlos Armio et al. Produção de alimentos para consumo doméstico no Paraná: caracterização e culturas alternativas. Londrina: lapar, 1994.

LIMA, Robson Santos. Otimização de perfis de reflexão GPR sobre manilhas de concreto e tubulações de PVC instaladas no Sítio Controlado de Geofísica Rasa do IAG/USP. Mestrado (Geofísica), Universidade de São Paulo, 2006.

PHILIPPI, Sonia Tucunduva et al. Pirâmide alimentar adaptada: guia para escolha dos alimentos Adapted food pyramid: a guide for a right food choice. Rev. Nutr, v. 12, n. 1, p. 65-80, 1999.

RESENDE, Francisco Vilela et al. Uso de cobertura morta vegetal no controle da umidade e temperatura do solo, na incidência de plantas invasoras e na produção da cenoura em cultivo de verão. Embrapa Hortaliças-Artigo em periódico indexado (ALICE), 2005.
RESH, Sigrid C. et al. Coarse root biomass for eucalypt plantations in Tasmania, Australia: sources of variation and methods for assessment. Trees, v. 17, n. 5, p. 389-399, 2003.

RIBEIRO, Maisa de Souza. O tratamento contábil dos créditos de carbono. 2005. Tese de Doutorado. Universidade de São Paulo.

ROCHA, Amanda Almeida et al. GPR 3D como método não invasivo para estudo do crescimento e biomassa de raízes de árvores de florestas tropicais. V Simpósio Brasileiro de Geofísica. 2012.

SANDMEIER, K. J. ReflexW. Version 6.0. WindowsTM $9 x / N T / 2000 / X P / 7$ - program for the processing of seismic, acoustic or eletromagnetic reflection, refraction and transmission data. Manual. 516p. 2011.

SOUZA, Amanda de M. et al. Alimentos mais consumidos no Brasil: Inquérito nacional de alimentação 2008-2009. Revista de Saúde Pública, v. 47, p. 190s-199s, 2013. 